\title{
The Effects of Long-Term Omega-3 Fatty Acid Supplementation on Cognition and Alzheimer's Pathology in Animal Models of Alzheimer's Disease: A Systematic Review and Meta-Analysis
}

\author{
Carlijn R. Hooijmans ${ }^{\mathrm{a}, *}$, Pieternel C.M. Pasker-de Jong ${ }^{\mathrm{b}}$, Rob B.M. de Vries ${ }^{\mathrm{a}}$ and \\ Merel Ritskes-Hoitinga ${ }^{\mathrm{a}}$ \\ ${ }^{a}$ Radboud University Nijmegen Medical Centre, Central Animal Laboratory and 3R Research Centre, Nijmegen, \\ The Netherlands \\ ${ }^{\mathrm{b}}$ Radboud University Nijmegen Medical Centre, Department of Epidemiology, Biostatistics and HTA, Nijmegen, \\ The Netherlands
}

Accepted 26 August 2011

\begin{abstract}
To date, only a few randomized clinical trials (RCTs) have investigated the effects of omega-3 fatty acids (FA) on Alzheimer's disease (AD). Some of these studies demonstrated that patients with very mild AD or mild cognitive impairment benefit from omega-3 FA treatment, but none showed significant improvements in cognitive function in patients with moderate or advanced AD. All these RCTs had a relatively short duration of supplementation, however, and we hypothesized that this might be one of the reasons why no effects of omega-3 FA supplementation could be observed in patients with "moderate" or "advanced" AD. Animal studies offer better possibilities for controlled long-term supplementation than clinical studies. Therefore, we performed a systematic review (SR) and meta-analysis of the literature that focused on effects of the relatively long-term omega-3 FA supplementation (minimum period; $10 \%$ of average total lifespan) on cognitive impairment, amyloid- $\beta$ pathology, and neuronal loss in animal models of AD. This SR shows that long-term omega-3 FA supplementation decreased the omega-6/omega-3 FA ratio and reduced the amount of amyloid- $\beta$ in experimental animal models of AD. Omega-3 FA supplementation also improved cognitive function; this effect appeared larger in rats compared to mice, and in males compared to females. Moreover, omega-3 FA supplementation diminished the amount of neuronal loss, especially in female animals. The results of this SR indicate that it might be worthwhile to perform new clinical trials with long-term omega-3 FA supplementation in $\mathrm{AD}$ patients.
\end{abstract}

Keywords: Alzheimer's disease, amyloid- $\beta$ peptides, animal models, cognition, docosahexaenoic acid, omega-3 fatty acids, pathology, systematic review

Supplementary data available online: http://dx.doi.org/10.3233/JAD-2011-111217

${ }^{*}$ Correspondence to: Carlijn R. Hooijmans, Radboud University Nijmegen Medical Centre, Central Animal Laboratory and 3R Research Centre, Geert Grooteplein Noord 29, Route 231, 6525 EZ Nijmegen, The Netherlands. Tel.: +0031 243668364; Fax: +0031 243616375; E-mail: C.Hooijmans@cdl.umcn.nl.

\section{INTRODUCTION}

Alzheimer's disease (AD) is a multifactorial neurodegenerative disease characterized by cognitive impairment, intracellular neurofibrillary tangles, 
synaptic loss, and extracellular amyloid plaques that accumulate in vulnerable brain regions. The cause of $\mathrm{AD}$ is still largely unknown and until now no cure for the disease is available. Therefore strategies for prevention and therapy are needed, especially because the number of people suffering from $\mathrm{AD}$ is rising quickly.

Clinical and epidemiological studies have shown that nutrition can affect the risk of the development of AD [1-7]. One of the dietary components that appear to play an important role is omega-3 fatty acids (FA).

Of the omega-3 polyunsaturated FAs, docosahexaenoic acid (DHA), is the most abundant one in the mammalian brain; very high levels can be found in neuronal membranes and the myelin sheath. Incorporation of omega-3 FA into neuronal membranes increases membrane fluidity; it also improves neurotransmission and signaling via increased receptor binding, enhances number and affinity of receptors, and improves the function of ion channels [8-11]. It is therefore not surprising that decreased serum DHA levels are associated with cognitive impairment [12-14]. Decreased DHA levels have also been observed in brain tissue of people with $\mathrm{AD}$, specifically in areas that mediate learning and memory [15]. As a result of these findings, various researchers have investigated the possibility that use of DHA supplements may reduce the risk of development or progression of $\mathrm{AD}$ (reviewed in [16-19]). Although the results of observational studies concerning the intake of fatty fish or omega-3 FA and the risk of cognitive decline or AD were conflicting [1, 5, 7, 20-31], randomized clinical trials (RCTs) studying the influence of omega-3 FA supplementation on $\mathrm{AD}$ or mild cognitive impairment (MCI) were performed.

Some of these RCTs showed that patients with very mild AD or MCI could benefit from omega-3 FA treatment. Patients with very mild AD in the OmegAD study showed a significant reduction in Mini-Mental State Examination (MMSE) decline rate due to omega3 FA treatment [32], and Chiu et al. [33] and Kotani et al. [34] showed significant improvements on cognition in patients with MCI. Chiu et al. also showed that general clinical function improves due to omega-3 FA supplementation in patients with mild to moderate AD [33]. Although the study of Quinn et al. showed a significantly slower decline in cognitive function in the APOE4 negative subgroup supplemented with DHA compared to placebo group [35], none of the other RCTs showed significant improvements in cognitive function in patients with moderate or advanced $\mathrm{AD}$ after omega-3 supplementation. This might partly be explained by the fact that, in all these RCTs, omega- 3
FA was supplemented relatively late in the course of disease; in addition, the durations of supplementation were relatively short (varying between 90 days and 18 months, which is a maximum of $1.8 \%$ of the total life span of a human).

Although these few studies give good insight into the effects of omega-3 FA on AD development, long-term clinical trials examining the efficacy of omega-3 FA against cognitive decline in $\mathrm{AD}$ are needed. In the ideal situation, long-term clinical studies, in which participants are supplemented with omega-3 FAs from young adult age, should be performed to confirm the beneficial effects of omega-3 FA supplementation. However, this kind of research is expensive, ethically complex, and time consuming and could only be performed in large collaborations subsidized by several governments; therefore we should focus for the time being on experimental animal models resembling the human situation as closely as possible to resolve the question whether or not relatively long-term omega-3 FA supplementation diminishes cognitive decline and reduces AD pathology.

In the last decade, several groups around the world used experimental animal models to study the longterm effects of omega-3 FA treatment on various aspects of AD. The results of these studies often originate from relatively small experiments and are quite heterogeneous. Systematically reviewing all these published papers in a objective and quantitative manner (unlike the widely used narrative reviews) has never been carried out before and might provide us with reliable and solid new evidence on whether or not longterm omega-3 FA treatment could be beneficial for patients with "advanced" AD. Therefore, the aim of this current study was to perform a systematic review (SR) and a meta-analysis of all available experimental evidence concerning the effects of long-term omega-3 FA supplementation on cognitive impairment, amyloid pathology, neurodegeneration, and brain FA levels in animal models of AD.

\section{MATERIALS AND METHODS}

\section{Search strategy and selection of the papers}

We searched the PubMed and Embase database for original articles concerning the effects of omega-3 FA supplementation in experimental animal models for AD until April 22, 2011. The search strategy was composed of three components: AD, omega-3 FA, and animals as described in Table 1, and was developed in cooperation with experts/information specialists 
Table 1

Search strategy in PubMed and Embase

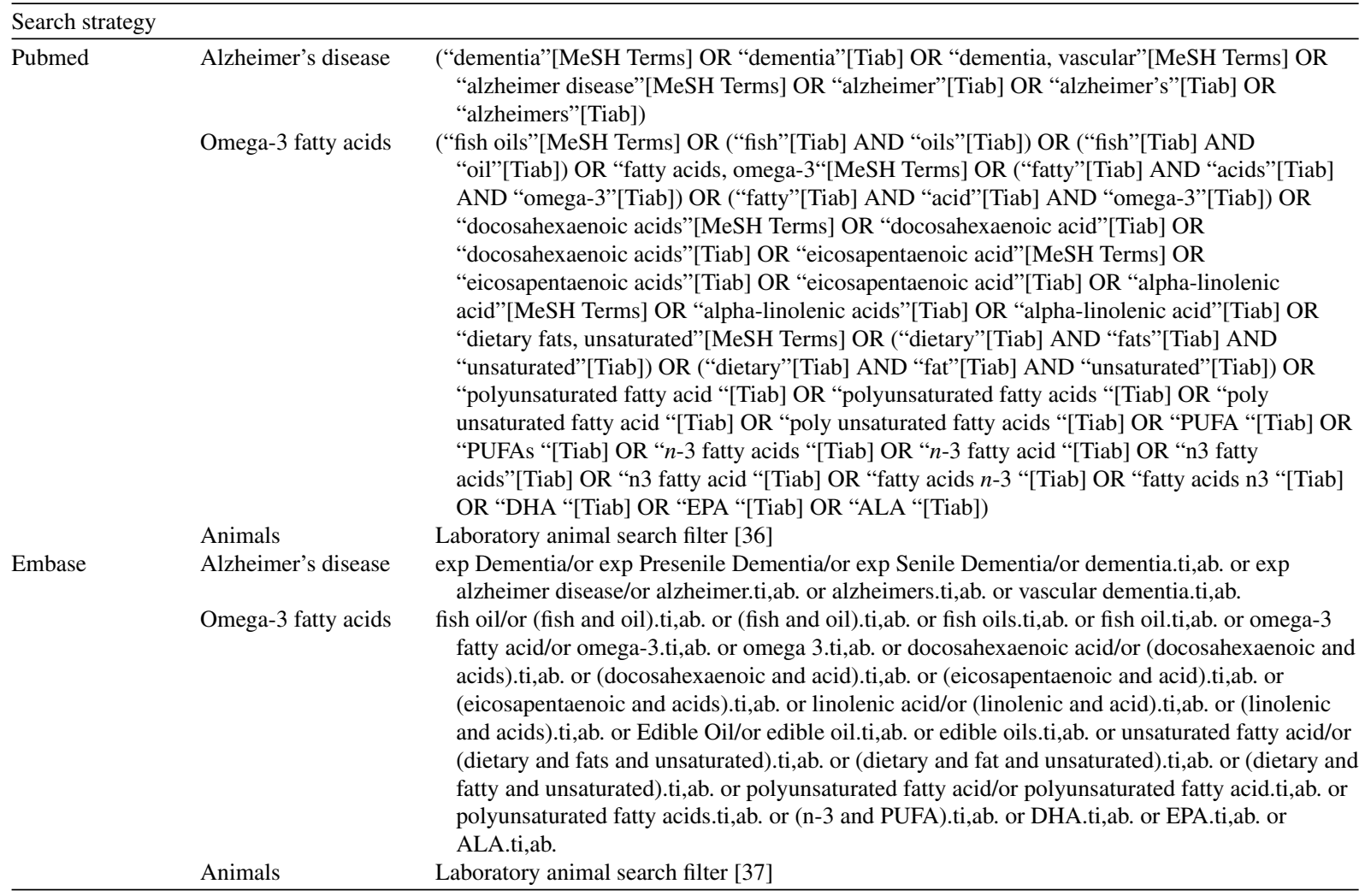

from the Medical Library of the Radboud University Nijmegen, the Netherlands. To detect all animal studies in both PubMed and Embase, search filters were used $[36,37]$. Furthermore, the reference lists of the selected relevant papers were screened by hand for potentially relevant new papers. No language restriction was used. If necessary, papers in languages other than English were translated by scientists (native speakers for that particular language) within the Radboud University Nijmegen Medical Centre. The selection of studies was performed on the basis of the title and abstract. In case of doubt, the entire publication was purchased and evaluated. Two investigators (C. Hooijmans and P. Pasker de Jong) independently screened all the abstracts for the inclusion criteria. Differences were resolved by a third investigator. Studies were included when they studied the effect of omega-3 FA supplementation in animal models for AD on behavior, cognition, neurodegeneration, brain circulation, or amyloid deposition. However, when they fulfilled one of the following exclusion criteria, the papers were excluded: 1) Not an original paper (review or letter etc.); 2) Omega-3 FA supplementation was combined with other (nutritional) components; 3) An animal model for $\mathrm{AD}$ without amyloid pathology was used; 4) Absence of a correct control group (control group had to be comparable to the experimental group, but without the omega-3 FA supplementation).

\section{Study characteristics and data extraction}

From the studies reviewed, the following data were extracted: animal species, kind of AD model, background, gender, number of animals in treatment and control group, randomization, blinding, kind of supplement, start and duration of supplementation, amount of omega-3 FAs in diet per day, route of administration, age of sacrificing the animals, number of animals excluded for statistical analysis, reason for excluding animals, outcome measures, and results (Table 2). Bibliographic details such as author, journal, and year of publication were also registered. Four outcome measures were assessed: cognition, amyloid- $\beta(\mathrm{A} \beta)$ deposition, neuron loss in the 
Table 2

Study characteristics of the included studies

\begin{tabular}{|c|c|c|c|c|c|c|c|c|c|c|}
\hline$\overline{\text { Study }}$ & Species & AD model & Sex & Supplement & $\begin{array}{l}\text { Route of } \\
\text { adminis- } \\
\text { tration }\end{array}$ & $\begin{array}{l}\text { Start supple- } \\
\text { mentation }\end{array}$ & $\begin{array}{l}\text { Amount of } \\
\text { supplement } \\
\text { (treated/control) }\end{array}$ & $\begin{array}{l}\text { Duration of } \\
\text { supplementa- } \\
\text { tion }\end{array}$ & Outcome measures & Comments \\
\hline $\begin{array}{l}\text { Arendash } \\
\text { [43] }\end{array}$ & Mouse & $\begin{array}{l}\mathrm{A} \beta \mathrm{PP} / \mathrm{PS} 1 \\
2 \times \mathrm{TgAD}\end{array}$ & $?$ & $n-3$ fatty acids & Diet & 2 months & $13 \% / 2.76$ & 5.5 months & $\begin{array}{l}\text { Cognition; MWM, } \\
\text { circular platform } \\
\text { platform recognition, } \\
\text { Y-maze, RAWM } \\
\text { A } \beta \text { deposition: Elisa }\end{array}$ & $\begin{array}{l}\text { Treated group also } \\
\text { contains higher level } \\
\text { of SFA } \\
\text { Contact with the } \\
\text { authors revealed the } \\
\text { use of both } \\
\text { males and females } \\
\text { (combined in one } \\
\text { group) }\end{array}$ \\
\hline $\begin{array}{l}\text { Arsenault } \\
\text { [54] }\end{array}$ & Mouse & $\begin{array}{c}\text { A } \beta P P / P S 1 / t a u \\
3 \times \text { TgAD }\end{array}$ & $?$ & DHA & Diet & 4 months & $0.6 \% / 0$ & $8-10$ months & $\begin{array}{l}\text { Brain fatty acids } \\
\text { Cognition: object } \\
\text { recognition } \\
\text { A } \beta \text { deposition: Elisa }\end{array}$ & $\begin{array}{l}\text { Contact with the } \\
\text { authors revealed the } \\
\text { use of both } \\
\text { Males and females } \\
\text { (combined in one } \\
\text { group) }\end{array}$ \\
\hline Calon [45] & Mouse & $\operatorname{tg} 2576$ & $\mathrm{M}+\mathrm{F}$ & DHA & Diet & 17 months & $0.6 \% /<0.01 \%$ & 103 days & Neuron loss: dendritic & $\begin{array}{l}\text { Both males and } \\
\text { females combined in } \\
\text { one group }\end{array}$ \\
\hline Calon [44] & Mouse & $\operatorname{tg} 2576$ & $\mathrm{M}+\mathrm{F}$ & DHA & Diet & 17 months & $0.6 \% /<0.01 \%$ & $3-5$ months & $\begin{array}{l}\text { Neuron loss: loss of } \\
\text { presynaptic markers } \\
\text { Brain fatty acids }\end{array}$ & $\begin{array}{l}\text { Both males and } \\
\text { females combined in } \\
\text { one group }\end{array}$ \\
\hline Green [38] & Mouse & $\begin{array}{l}\mathrm{A} \beta \mathrm{PP} / \mathrm{PS} 1 / \mathrm{tau} \\
3 \times \mathrm{TgAD}\end{array}$ & $M+F$ & DHA & Diet & 3 months & $1.3 \% / 0$ & $\begin{array}{l}3,6 \text { or } 9 \\
\text { months }\end{array}$ & $\mathrm{A} \beta$ deposition: IHC & $\begin{array}{l}\text { Study contains } 3 \\
\text { separate } \\
\text { experimental groups } \\
\text { ( } 3,6 \text { and } 9 \text { months of } \\
\text { supplementation) } \\
\text { Both males and } \\
\text { females combined in } \\
\text { one group }\end{array}$ \\
\hline $\begin{array}{l}\text { Hashimoto } \\
\text { [48] }\end{array}$ & Rat & $A \beta$ infused rats & M & $\begin{array}{l}\text { DHA in gum } \\
\text { arabic solution }\end{array}$ & Oral & 25 weeks & $\begin{array}{l}300 \mathrm{mg} / \mathrm{kgBW} / \text { day } \\
\text { vs } 0\end{array}$ & 15 weeks & $\begin{array}{l}\text { Cognition: avoidance } \\
\text { learning } \\
\text { Neuron loss: cell death } \\
\text { Brain fatty acids }\end{array}$ & $\begin{array}{l}\text { DHA is administered } \\
12 \text { weeks before and } \\
3 \text { weeks } \\
\text { After surgery and } \mathrm{A} \beta \\
\text { infusion }\end{array}$ \\
\hline $\begin{array}{l}\text { Hashimoto } \\
\text { [50] }\end{array}$ & Rat & $\mathrm{A} \beta$ infused rats & M & $\begin{array}{l}\text { DHA in gum } \\
\text { arabic solution }\end{array}$ & oral & 26 weeks & $\begin{array}{l}300 \mathrm{mg} / \mathrm{kgBW} / \text { day } \\
\text { vs } 0\end{array}$ & 12 weeks & $\begin{array}{l}\text { Cognition: Radial Arm } \\
\text { Maze } \\
\text { Brain fatty acids }\end{array}$ & $\begin{array}{l}\text { DHA is administered } \\
\text { after surgery }\end{array}$ \\
\hline
\end{tabular}


Table 2

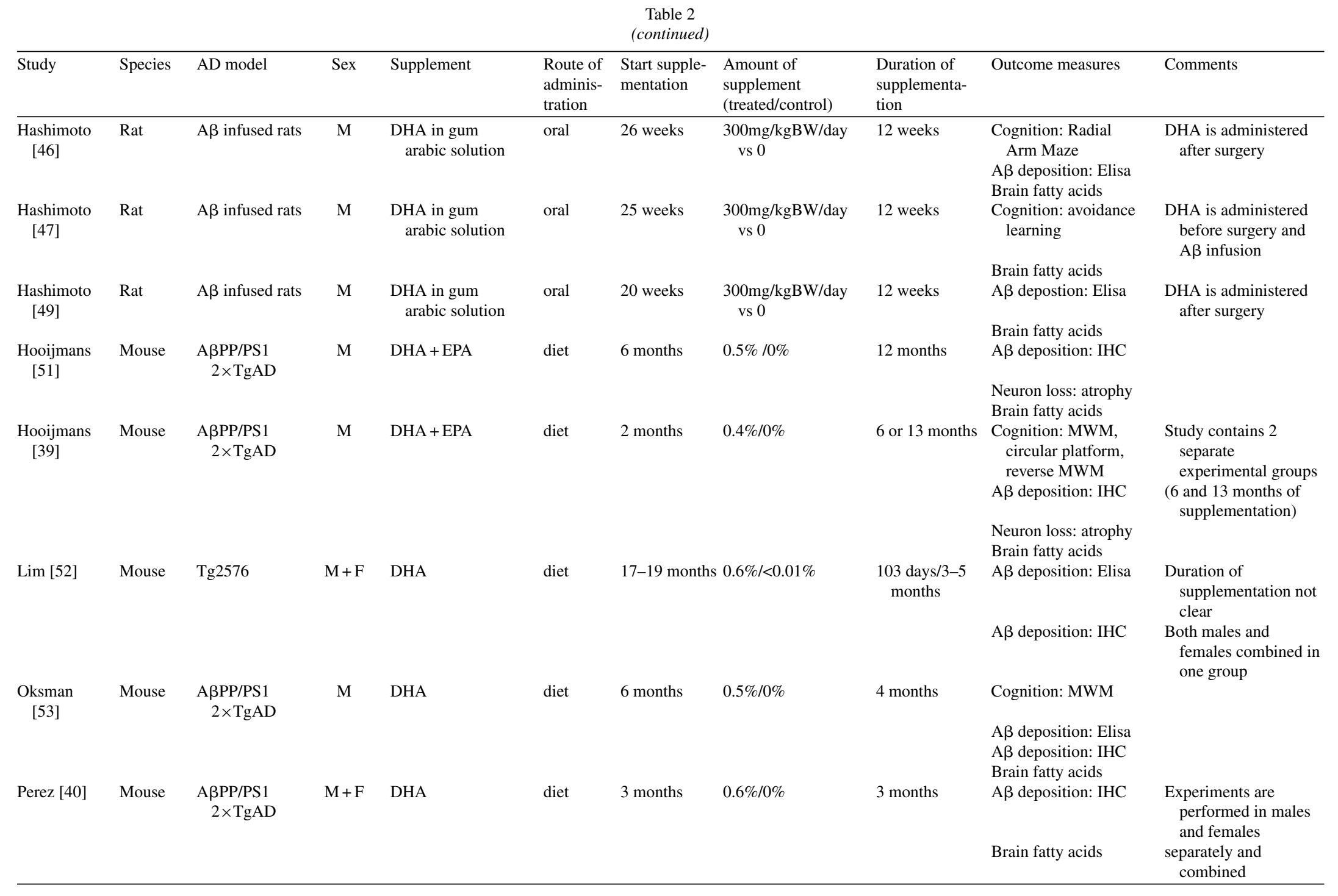


hippocampus, and cortical FA levels. The six most studied brain polyunsaturated FAs were analyzed in our meta-analysis: linoleic acid (C18:2n-6), arachidonic acid (C20:4n-6), adrenic acid (C22:4n6), $\alpha$-linolenic acid (C18:3n-3), eicosapentaenoic acid (EPA, C20:5n-3), docasahexaenoic acid (DHA, $\mathrm{C} 22: 6 n-3)$. Also the ratio between the total amount of $n-6$ and $n-3$ FA in cortical brain tissue was determined. For the outcome measure "cognition", results of studies were included in which learning and/or memory functions had been determined.

Data could be extracted in case the authors had explicitly described the measure of interest as a measure for neuron loss, synapse loss, or neurodegeneration, such as the width of the dentate gyrus of the hippocampus, histone-associated DNA fragments, synaptic marker loss, etc. From all outcome measures that were assessed, the means, standard deviations (SDs) or standard errors (SE), and number of animals per group (n) were recorded. When data were only presented graphically, attempts were made to obtain data from the authors; if these were not available, data were measured using digital ruler software where possible (Universal Desktop Ruler). If a study contained groups with different genders or several age groups that were investigated separately (i.e., [38-40]), the age or gender groups were analyzed as if they were separate studies.

\section{Quality assessment}

We assessed the study quality of the included studies using the criteria described in Table 3. These criteria are based on the presence and short description of important study characteristics such as age, species, gender, duration of supplementation, amount of omega-3 in diet, etc., but also on the assessment of the internal validity - performance bias (differences in care provided?), exclusion bias (differences in withdrawal from studies?), detection bias (differences in measurement of outcomes?), selection bias (biased allocation to comparison groups?) - and external validity - population, intervention, outcome, precision, etc. - as described in the book of Egger et al. [41].

The quality of all studies was assessed independently by two reviewers (C. Hooijmans and P. Pasker de Jong). It should be noted that the quality assessment assesses mainly the reporting quality. Negative judgment does not necessarily indicate that the experiment has been carried out insufficiently; it indicates inadequate information to assess quality.

\section{Quantitative data synthesis and statistical analysis}

For each outcome measure in each study, the standardized mean difference (SMD) was calculated (the mean of the experimental group minus the mean of the control group divided by the pooled SD of the two groups). Despite anticipated heterogeneity, the individual SMDs were pooled whenever possible (starting from two studies or more) to obtain an overall SMD and $95 \%$ confidence interval. Where outcomes were measured repeatedly using different methods, we chose the time point at which the measured efficacy was greatest.

To account for anticipated heterogeneity, we used the random effects model [42] in which some heterogeneity beyond sampling errors is allowed. To explore possible causes for heterogeneity, subgroup analyses were planned for the following study characteristics: gender (male, female, or mixed), species (mice/rats), duration of supplementation (shorter or longer than 6 months), starting age of supplementation (young adults: mice 8-14 weeks, rats 16-22 weeks; aged adults: mice $>14$ weeks, rats $>22$ weeks), and start of supplementation before or after inducing $\mathrm{AD}$ in an animal model. We have chosen biological rather than methodological characteristics to try to explain the possible causes of heterogeneity. A subgroup was defined as a group containing a minimum of two studies. Groups were considered different in case of approximately one SEM of the SMD difference $(\alpha \approx 30 \%)$. Because of this high $\alpha$ and low power, no statistical tests were used to confirm differences between subgroups. For the same reason, observed differences between small subgroups should be interpreted with caution and be used for constructing new hypotheses, rather than for drawing final conclusions. To detect publication bias, funnelplots were created and explored. Meta-analysis was performed with Review Manager (RevMan Version 5.0. Copenhagen: The Nordic Cochrane Centre, The Cochrane Collaboration, 2008). Meta-regression was then carried out for each of the outcome measures and the study characteristics gender, species, and duration of supplementation in SPSS 16.0 using a macro written by David B. Wilson (E-mail: dwilsonb@gmu.edu). We used inverse variance weighted generalized least squares regression with full-information maximum likelihood estimates. We present R-squared as a measure of explanation of heterogeneity by the total model, and studied the coefficients of the variables to determine effect modification. As the power was low, we decided on determining effect modification (i.e., heterogeneity) 
Table 3

Quality assessment of the included studies

\begin{tabular}{|c|c|c|c|c|c|c|c|c|c|c|c|c|c|c|c|c|c|}
\hline Study Quality: & 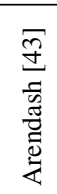 & 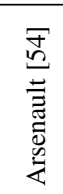 & $\begin{array}{l}\frac{\sqrt[n]{ \pm}}{\tilde{\delta}} \\
\frac{\tilde{\pi}}{\tilde{J}}\end{array}$ & $\begin{array}{l}\frac{\Xi}{ \pm} \\
\frac{\delta}{\tilde{U}}\end{array}$ & 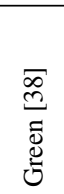 & 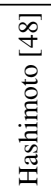 & 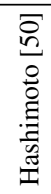 & $\begin{array}{l}\overline{0} \\
+1 \\
0 \\
0 \\
0 \\
0 \\
0 \\
0 \\
0 \\
0\end{array}$ & 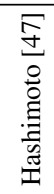 & 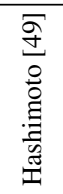 & 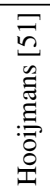 & 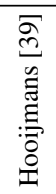 & $\begin{array}{l}\overline{\widetilde{N}} \\
\text { 䍐 }\end{array}$ & 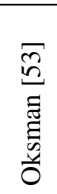 & $\frac{\bar{D}}{\underset{D}{D}}$ & 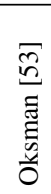 & 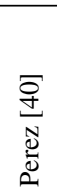 \\
\hline Research question specified and clear? & $\sqrt{ }$ & $\sqrt{ }$ & $\sqrt{ }$ & $\sqrt{ }$ & $\mathrm{no}^{7}$ & $\sqrt{ }$ & $\sqrt{ }$ & $\sqrt{ }$ & $\sqrt{ }$ & $\sqrt{ }$ & $\sqrt{ }$ & $\sqrt{ }$ & $\sqrt{ }$ & $\sqrt{ }$ & $\sqrt{ }$ & $\sqrt{ }$ & $\sqrt{ }$ \\
\hline $\begin{array}{l}\text { Outcome measures relevant for } \mathrm{AD} \text { research } \\
\text { Are the characteristics of study population clear? }\end{array}$ & $\sqrt{ }$ & $\sqrt{ }$ & $\sqrt{ }$ & $\sqrt{ }$ & $\sqrt{ }$ & $\sqrt{ }$ & $\sqrt{ }$ & $\sqrt{ }$ & $\sqrt{ }$ & $\sqrt{ }$ & $\sqrt{ }$ & $\sqrt{ }$ & $\sqrt{ }$ & $\sqrt{ }$ & $\sqrt{ }$ & $\sqrt{ }$ & $\sqrt{ }$ \\
\hline Species & $\sqrt{ }$ & $\sqrt{ }$ & $\sqrt{ }$ & $\sqrt{ }$ & $\sqrt{ }$ & $\sqrt{ }$ & $\sqrt{ }$ & $\sqrt{ }$ & $\sqrt{ }$ & $\sqrt{ }$ & $\sqrt{ }$ & $\sqrt{ }$ & $\sqrt{ }$ & $\sqrt{ }$ & $\sqrt{ }$ & $\sqrt{ }$ & $\sqrt{ }$ \\
\hline Background/generation & $\sqrt{ }$ & no & no & no & no & $\sqrt{ }$ & $\sqrt{ }$ & $\sqrt{ }$ & $\sqrt{ }$ & $\sqrt{ }$ & $\sqrt{ }$ & $\sqrt{ }$ & no & $\sqrt{ }$ & $\sqrt{ }$ & $\sqrt{ }$ & $\sqrt{ }$ \\
\hline Sex (and distribution) & no & no & no & $\sqrt{ }$ & no & $\sqrt{ }$ & $\sqrt{ }$ & $\sqrt{ }$ & $\sqrt{ }$ & $\sqrt{ }$ & $\sqrt{ }$ & $\sqrt{ }$ & no & $\sqrt{ }$ & $\sqrt{ }$ & $\sqrt{ }$ & $\sqrt{ }$ \\
\hline Age & $\sqrt{ }$ & $\sqrt{ }$ & $\sqrt{ }$ & $\sqrt{ }$ & $\sqrt{ }$ & $\sqrt{ }$ & $\sqrt{ }$ & $\sqrt{ }$ & $\sqrt{ }$ & $\sqrt{ }$ & $\sqrt{ }$ & $\sqrt{ }$ & $\sqrt{ }^{6}$ & $\sqrt{ }$ & $\sqrt{ }$ & $\sqrt{ }$ & $\sqrt{ }$ \\
\hline Presence and correct control group? & $\sqrt{ }$ & $\sqrt{ }$ & $\sqrt{ }$ & $\sqrt{ }$ & $\sqrt{ }$ & $\sqrt{ }$ & $\sqrt{ }$ & $\sqrt{ }$ & $\sqrt{ }$ & $\sqrt{ }$ & $\sqrt{ }$ & $\sqrt{ }$ & $\sqrt{ }$ & $\sqrt{ }$ & $\sqrt{ }$ & $\sqrt{ }$ & $\sqrt{ }$ \\
\hline $\begin{array}{l}\text { Where the groups similar at baseline (if not randomized think of } \\
\text { weight and sex etc)? }\end{array}$ & $\sqrt{ }$ & no $^{3}$ & $\sqrt{ }$ & $\sqrt{ }$ & no $^{3}$ & $\sqrt{ }$ & $\sqrt{ }$ & $\sqrt{ }$ & $\sqrt{ }$ & $\sqrt{ }$ & $\sqrt{ }$ & $?$ & no ${ }^{6}$ & $\sqrt{ }$ & $\sqrt{ }$ & $\sqrt{ }$ & $\sqrt{ }$ \\
\hline Is the experiment randomized? & $\sqrt{ }$ & no & $\sqrt{ }$ & $\sqrt{ }$ & no & $\sqrt{ }^{4}$ & $\sqrt{ }$ & $\sqrt{ }$ & $\sqrt{ }$ & $\sqrt{ }$ & no & no & no & no & $\sqrt{ }$ & no & $\sqrt{ }$ \\
\hline ioned (DHA, EPA or combination etc)? & $\sqrt{ }$ & $\sqrt{ }$ & $\sqrt{ }$ & $\sqrt{ }$ & $\sqrt{ }$ & $\sqrt{ }$ & $\sqrt{ }$ & $\sqrt{ }$ & $\sqrt{ }$ & $\sqrt{ }$ & $\sqrt{ }$ & $\sqrt{ }$ & $\sqrt{ }$ & $\sqrt{ }$ & $\sqrt{ }$ & $\sqrt{ }$ & $\sqrt{ }$ \\
\hline Age when supplementation started mentioned? & $\sqrt{ }$ & $\sqrt{ }$ & $\sqrt{ }^{2}$ & $\sqrt{ }^{2}$ & $\sqrt{ }$ & $\sqrt{ }$ & $\sqrt{ }$ & $\sqrt{ }$ & $\sqrt{ }$ & no $^{8}$ & $\sqrt{ }$ & $\sqrt{ }$ & $\sqrt{ }^{2}$ & $\sqrt{ }$ & $\sqrt{ }$ & $\sqrt{ }$ & $\sqrt{ }$ \\
\hline Duration of supplementation clear and specified? & $\sqrt{ }$ & no ${ }^{10}$ & $\sqrt{ }$ & no ${ }^{10}$ & $\sqrt{ }$ & $\sqrt{ }$ & $\sqrt{ }$ & $\sqrt{ }$ & $\sqrt{ }$ & $\sqrt{ }$ & $\sqrt{ }$ & $\sqrt{ }$ & no ${ }^{10}$ & $\sqrt{ }$ & $\sqrt{ }$ & $\sqrt{ }$ & $\sqrt{ }$ \\
\hline Amount of o & $\sqrt{ }$ & $\sqrt{ }$ & $\sqrt{ }$ & $\sqrt{ }$ & $\sqrt{ }$ & $\sqrt{ }$ & $\sqrt{ }$ & $\sqrt{ }$ & $\sqrt{ }$ & $\sqrt{ }$ & $\sqrt{ }$ & $\sqrt{ }$ & $\sqrt{ }$ & $\sqrt{ }$ & $\sqrt{ }$ & $\sqrt{ }$ & $\sqrt{ }$ \\
\hline Administration route specified (diet or oral etc)? & $\sqrt{ }$ & $\sqrt{ }$ & $\sqrt{ }$ & $\sqrt{ }$ & $\sqrt{ }$ & $\sqrt{ }$ & $\sqrt{ }$ & $\sqrt{ }$ & $\sqrt{ }$ & $\sqrt{ }$ & $\sqrt{ }$ & $\sqrt{ }$ & $\sqrt{ }$ & $\sqrt{ }$ & $\sqrt{ }$ & $\sqrt{ }$ & $\sqrt{ }$ \\
\hline $\begin{array}{l}\text { Is the timing of the supplementation during the day specified and } \\
\text { similar in both groups? }\end{array}$ & $\mathrm{no}^{0}$ & no ${ }^{0}$ & no $^{0}$ & no $^{0}$ & no ${ }^{0}$ & no $^{0}$ & no $^{0}$ & no $^{0}$ & no ${ }^{0}$ & no $^{0}$ & $\mathfrak{J}^{1}$ & 1 & no ${ }^{0}$ & 1 & no ${ }^{0}$ & 1 & no ${ }^{0}$ \\
\hline Methods used for outcome assessment the same in both groups? & $\sqrt{ }$ & $\sqrt{ }$ & $\sqrt{ }$ & $\sqrt{ }$ & $\sqrt{ }$ & $\sqrt{ }$ & $\sqrt{ }$ & $\sqrt{ }$ & $\sqrt{ }$ & $\sqrt{ }$ & $\sqrt{ }$ & $\sqrt{ }$ & $\sqrt{ }$ & $\sqrt{ }$ & $\sqrt{ }$ & $\sqrt{ }$ & $\sqrt{ }$ \\
\hline Drop outs described for each group separately? & no & no & no & no & no & no & no & no & no & no & ? & $?$ & $\sqrt{ }$ & no & no & no & no \\
\hline Blinded outcome assessment? & no & no & no & no & $\sqrt{ }$ & no & no & no & no & no & no & no & no & no ${ }^{9}$ & no & no ${ }^{9}$ & no \\
\hline Was the outcome assessment randomized & no & no & no & no & no & no & no & no & no & no & no & no & no & no & no & no & no \\
\hline Total number of animals included in statistical analyses clear? & no & $\sqrt{ }$ & no & no & $?$ & $\sqrt{ }^{5}$ & $\sqrt{ }$ & $\sqrt{ }$ & $\sqrt{ }$ & no & $\sqrt{ }$ & $\sqrt{ }$ & $\sqrt{ }$ & no & no & no & no \\
\hline Age of sacrificing animals mentioned? & $\sqrt{ }$ & $\sqrt{ }$ & $\sqrt{ }$ & $\sqrt{ }$ & $\sqrt{ }$ & $\sqrt{ }$ & $\sqrt{ }$ & $\sqrt{ }$ & $\sqrt{ }$ & $\mathrm{no}^{8}$ & $\sqrt{ }$ & $\sqrt{ }$ & $\sqrt{ }$ & $\sqrt{ }$ & $\sqrt{ }$ & $\sqrt{ }$ & $\sqrt{ }$ \\
\hline re (items $\sqrt{ }$ ) & 15 & 12 & 14 & 14 & 12 & 17 & 17 & 17 & 17 & 14 & 17 & 17 & 13 & 16 & 16 & 16 & 16 \\
\hline Quality score (\%) & 71 & 57 & 67 & 67 & 57 & 81 & 81 & 81 & 81 & 67 & 81 & 81 & 62 & 76 & 76 & 76 & 76 \\
\hline
\end{tabular}

$\sqrt{ }=$ fulfilling the criterion, no $=$ not fulfilling the criterion, $?=$ not enough information to determine whether or not the raised criterion is fulfilled. 0 : It is not clearly stated whether the diet is fed ad libitum or not and when the animals received their food. 1 - Authors mention that the food is given ad libitum. 2 Not precise, authors say "at least 17 months, or 17 months. 3 - The scientists did not describe the distribution of weight or gender in the groups at the start of the experiment. 4 - Partly. 5 - Answer is "YES" when in 50\% of the cases the number of animals is mentioned. 6 - Authors mention that the animals are between 17-19 months old, which is not precise. 7 - The research question is incomplete. 8 - The design of the experiment was not clear to us, and because of that the age when supplementation started and when the mice were sacrificed could not be determined. 9 - Partly, only assessment of $A \beta$ deposition is blinded. 10 - Duration of supplementation varied (for example 3-5 months). 
on the basis of at least one SEM difference in SMD between the subgroups.

\section{RESULTS}

\section{Description of the included studies}

The search strategy described in Table 1 retrieved 313 papers in PubMed and 514 papers in Embase. Twenty-seven papers met our selection criteria. After correction for duplicate findings, 15 original studies remained. The characteristics of these studies [38-40, 43-54] are shown in Table 2.

There was a large variation in most study characteristics. Ten studies were performed with transgenic mice, and five studies used $A \beta$-infused rats. Eight studies used only males, and five studies used both genders. Two studies did not mention which gender was used, but after contacting the authors it became clear that the experimental population consisted of both genders. Two of the studies, which were performed in rats, started DHA supplementation before creating the experimental $\mathrm{AD}$ model (infusing $\mathrm{A} \beta$ peptide in the rat cerebral ventricle). The age at the start of supplementation (2-19 months of age) and the duration of supplementation (3-13 months) varied greatly between the studies. Because of the large variation in study design, subgroup analyses were performed for gender, species used, and duration of supplementation only.

Data of the four outcome measures were collected: cognition, $\mathrm{A} \beta$ deposition, neuron loss/ neurodegeneration, and brain FA levels. Fourteen experiments (extracted from 10 papers) studied the effects of omega- 3 FAs on $\mathrm{A} \beta$ deposition in AD animal models and could be used in the meta-analysis. Eight papers presented a measure for cognition (defined as a measure for learning or memory capacity). Brain FA content was reported in 13 of the 15 papers. From 12 of these studies, data could be included in meta-analysis (one study contained duplicate data). Neuron loss or a measure for neurodegeneration was presented in five papers.

\section{Study quality}

Table 3 shows the results of the quality assessment of the 15 studies included in this SR. The median quality score was that 16 items out of 21 had been reported. The lowest score was 12 items (57\%), and the highest scoring studies reported 17 items out of 21 (81\%). Although randomization, blinding, and description of the number of dropouts are key quality measures in the quality assessment of clinical trials, only $60 \%$ of the studies included in this SR randomly allocated the experimental units across the treatment groups. None of the papers described the method of randomization or randomizing the order of outcome assessment across the groups. Only $6 \%$ of the studies mentioned blinding of the outcome assessment, and only $20 \%$ of the studies described the number of dropouts per group. The number of studies included in this SR is relatively small, and the quality assessment of these studies assesses the quality of reporting more than the quality of the carrying out of an animal study. Therefore the results of the quality assessment were not used for a sensitivity analysis.

\section{Publication bias}

The presence of publication bias was assessed for the outcome measures learning and $A \beta$ deposition. The variation in SE was too small, however, to interpret the funnel plots reliably (data not shown).

\section{Effects of omega-3 supplementation}

\section{A $\beta$ deposition}

Fourteen experiments studied the effect of omega-3 FA supplementation on the amount of $A \beta$ in animal models for AD. Eight of these experiments showed significantly reduced $A \beta$ levels due to omega3 FA supplementation. Overall analysis showed that omega-3 FA supplementation reduced the amount of $\mathrm{A} \beta$ in animal models for AD (Fig. 1; SMD -1.43 $[-1.96,-0.89]$ ). Supplementary Figure 1 (available online: http://www.j-alz.com/issues/28/vol28-1. html\#supplementarydata03) shows different subgroups for $A \beta$ deposition. No clear differences between brain regions or types of $A \beta$ measured were observed. In the meta-regression, the very moderate heterogeneity of results that was present was not explained by any of the variables included in the model. $\mathrm{R}$-squared of the model (the proportion of variance explained by the model) was $8 \%$.

\section{Cognition}

Ten studies described the effect of omega-3 FA supplementation on cognition; nine of these studies could be included in the meta-analysis. Five of these nine studies used the Morris water maze test, two studies used the avoidance learning test, one used the object recognition, and one used the radial arm maze. Of the studies included in the meta-analysis, five 


\begin{tabular}{|c|c|c|c|c|}
\hline Study or Subgroup & $\begin{array}{l}\text { Std. Mean Difference } \\
\text { IV, Random, } 95 \% \mathrm{Cl}\end{array}$ & $\begin{array}{l}\text { Std. Mean } \\
\text { IV, Rando }\end{array}$ & $\begin{array}{l}\text { Difference } \\
\mathrm{om}, 95 \% \mathrm{Cl}\end{array}$ & \\
\hline Arendash 2007 & $-0.69[-1.75,0.36]$ & & & \\
\hline Arsenault, 2011 & $-0.41[-1.24,0.43]$ & & & \\
\hline Green 200712 months & $-2.10[-3.63,-0.57]$ & & & \\
\hline Green 20076 months & $-2.49[-4.16,-0.83]$ & & & \\
\hline Green 20079 months & $-1.67[-3.06,-0.27]$ & & & \\
\hline Hashimoto $2005 \mathrm{~b}$ & $-2.33[-3.73,-0.93]$ & . & & \\
\hline Hashimoto 2008 & $-1.62[-2.68,-0.55]$ & & & \\
\hline Hooijmans 2007 & $-4.53[-7.02,-2.05]$ & & & \\
\hline Hooijmans 2009 - 8 months & $-0.59[-1.67,0.48]$ & & & \\
\hline Hooijmans $2009-15$ months & $-2.02[-3.39,-0.65]$ & & & \\
\hline Lim 2005 & $-0.64[-2.01,0.73]$ & & & \\
\hline Oksman 2006 & $-1.95[-2.86,-1.04]$ & $\rightarrow$ & & \\
\hline Perez 2010 - female & $-2.20[-4.50,0.10]$ & & & \\
\hline Perez 2010 - male & $0.60[-0.85,2.04]$ & & & \\
\hline Total $(95 \% \mathrm{Cl})$ & $-1.43[-1.96,-0.89]$ & & & \\
\hline \multicolumn{2}{|c|}{$\begin{array}{l}\text { Heterogeneity: } \mathrm{Tau}^{2}=0.56 ; \mathrm{Chi}^{2}=30.62, \mathrm{df}=13(P=0.004) ; \mathrm{I}^{2}=58 \% \\
\text { Test for overall effect: } Z=5.22(P=0.00001)\end{array}$} & $\begin{array}{ll}-10 & -5 \\
\end{array}$ & $0 \quad 5$ & $\overrightarrow{10}$ \\
\hline
\end{tabular}

Fig. 1. Forest plot (effect size and $95 \% \mathrm{CI}$ ) of individual studies of omega-3 FA supplementation on amyloid- $\beta$ deposition in experimental animal models of Alzheimer's disease.

A

\begin{tabular}{|c|c|c|}
\hline \multicolumn{2}{|c|}{ Study or Subgroup } & $\begin{array}{r}\text { Std. Mean Differ } \\
\text { IV, Random, } 9\end{array}$ \\
\hline \multicolumn{2}{|c|}{ Arendash 2007} & $0.37[-0.62$ \\
\hline \multicolumn{2}{|c|}{ Arsenault, 2011} & $0.76[-0.4$ \\
\hline \multicolumn{2}{|c|}{ Calon 2004} & $0.43[-0.7$ \\
\hline \multicolumn{2}{|c|}{ Hashimoto 2002} & $2.29[1.2$ \\
\hline \multicolumn{2}{|c|}{ Hashimoto $2005 b$} & $1.06[-0.0$ \\
\hline \multicolumn{2}{|c|}{ Hashimoto 2006} & $7.68[4.69$ \\
\hline \multicolumn{2}{|c|}{ Hooijmans 2009 - 8 months } & $1.00[0.1]$ \\
\hline \multicolumn{2}{|c|}{ Hooijmans $2009-15$ months } & $1.52[0.2$ \\
\hline \multicolumn{2}{|c|}{ Oksman 2006} & $0.071-0$ \\
\hline \multicolumn{2}{|l|}{ Total $(95 \% \mathrm{Cl})$} & $1.23[0.46$ \\
\hline \multicolumn{3}{|c|}{$\begin{array}{l}\text { Heterogeneity: } \operatorname{Tau}^{2}=0.99 ; \mathrm{Chi}^{2}=36.30, \mathrm{df}=8( \\
\text { Test for overall effect: } Z=3.15(P=0.002)\end{array}$} \\
\hline \multicolumn{3}{|l|}{ B } \\
\hline Subgroups & Ef & ffect size and $\mathrm{Cl}$ \\
\hline Overall & 9 & $1.23[0.46,1.99]$ \\
\hline Male & 6 & $1.72[0.58,2.86]$ \\
\hline Female & 0 & ne \\
\hline Mixed & 3 & $0.50[-0.14,1.13]$ \\
\hline Mice & 6 & $0.56[0.15,0.98]$ \\
\hline Rats & 3 & $3.17[0.77,5.57]$ \\
\hline
\end{tabular}

Fig. 2. (a) Forest plot (effect size and $95 \%$ CI) and (b) subgroup analysis of individual studies of omega-3 FA supplementation on cognition in experimental animal models of Alzheimer's disease.

reported significantly improved cognition in animals supplemented with omega-3 FAs compared to controls. Overall analysis showed that omega-3 FA supplementation improved cognition (Fig. 2; SMD 1.23 [0.46, 1.99]). Subgroup analysis revealed that this effect was more pronounced in rats compared to mice (rats: SMD 3.17 [0.77, 5.57], mice: SMD 0.56 [0.15, 0.98]) and in males compared to the mixed gender groups (males: SMD 1.72 [0.58, 2.86], mixed: SMD 0.50 $[-0.14,1.13])$. The two studies with the largest effect size (Fig. 2a) started omega-3 supplementation before creating the experimental AD model (infusing A $\beta$ peptide in the rat cerebral ventricle). Sensitivity analysis revealed that, if the studies that started omega-3 FA supplementation before creating the experimental AD model are excluded from the meta-analysis, the overall effect on cognition remains significantly improved in omega-3 supplemented animals compared to the controls (SMD 0.61 [0.23, 0.99]). In the meta-regression, the effect of species remained, but in this simultaneous 


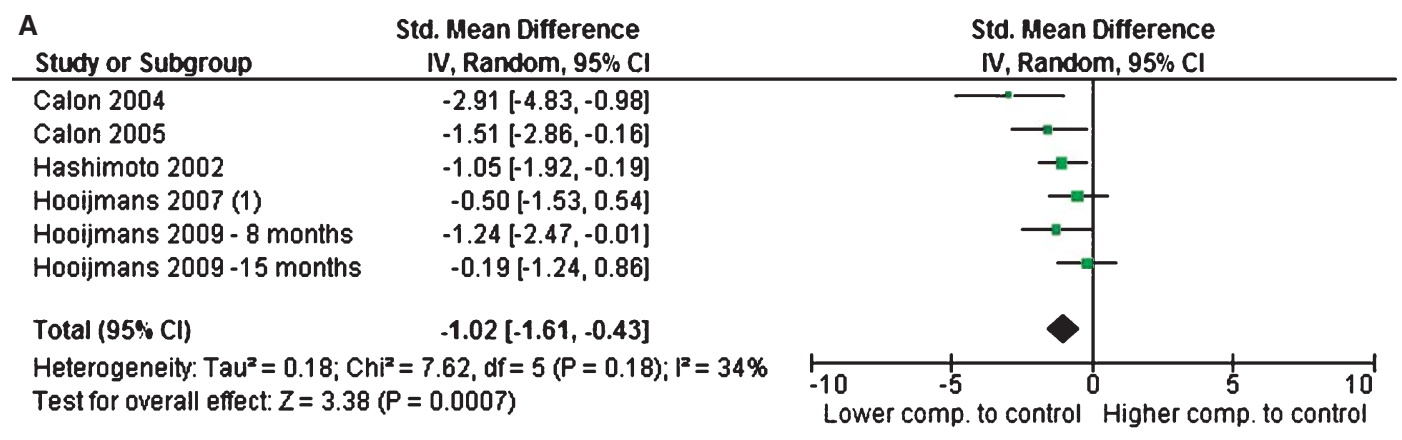

(1) unpublished data

B

\begin{tabular}{|c|c|c|}
\hline Subgroups & $\mathrm{n}$ & Effect size and $\mathrm{Cl}$ \\
\hline Overall & 6 & $-1.02[-1.61,-0.43]$ \\
Male & 4 & $-0.75[-1.26,-0.24]$ \\
Female & 0 & ne \\
Mixed & 2 & $-2.03[-3.36,-0.70]$ \\
\hline
\end{tabular}

Fig. 3. (a) Forest plot (effect size and 95\% CI) and (b) subgroup analysis of individual studies of omega-3 FA supplementation on neuron loss/neurodegeneration in experimental animal models of Alzheimer's disease.

analysis the effect of gender disappeared, suggesting confounding by species. Duration of supplementation explained a small part of the heterogeneity as well. R-squared of the model was $49 \%$. However, heterogeneity remained strong.

\section{Neuron loss/neurodegeneration}

In four out of six experiments that were included in meta-analysis, the amount of hippocampal neuronal loss/neurodegeneration significantly decreased with omega-3 FA supplementation in animal models for AD. Meta-analysis of all six studies investigating hippocampal neuronal loss/neurodegeneration revealed a diminished amount of neuronal loss in AD animals supplemented with omega-3 FA compared to controls (Fig. 3a; SMD - $1.02[-1.61,-0.43]$ ). Subgroup analysis (Fig. 3b) revealed that this effect was largest in the mixed gender group (SMD - 2.03 [-3.36, -0.70]) compared to the male groups (SMD $-0.75[-1.26$, $-0.24]$ ). In the meta-regression, most of the heterogeneity was explained by gender. The other variables did not add anything. R-squared of the model was $86 \%$.

\section{Fatty acid levels}

Omega-6 FAs. Both arachidonic acid (AA) and adrenic acid levels in the cortex of experimental AD models decreased in response to omega-3 FA supplementation (Fig. 4a; AA: SMD -1.86 [-2.60, -1.11], adrenic acid: SMD $-2.75[-4.03,-1.47])$. Linoleic acid levels remained unaltered. Subgroup analysis revealed a gender effect for $\mathrm{AA}$, adrenic acid, and linoleic acid. Linoleic acid levels were increased in the mixed gender group compared to the group with just males (Fig. 4b; mixed gender: SMD 2.03 [0.67, 3.39], males: SMD 0.09 [-0.76, 0.93]). The observed decrease in AA and adrenic acid levels were larger in the mixed gender group compared to the group with just males (Fig. 4).

Omega-3 FAs. In all 14 studies included in this SR, DHA was one of the supplemented omega-3 FAs (Table 2). Thirteen studies could be included in metaanalysis. Of those 13 studies, 10 showed a significant increase in DHA levels. Clearly, DHA/omega-3 FA supplementation resulted in increased levels of DHA in cortical brain tissue of experimental AD models (Fig. 5a; SMD 2.14 [1.28, 2.99]). This effect seemed to be even larger in female animals compared to males alone and in mice compared to rats (Fig. 5b; mixed gender: SMD 2.67 [1.09, 4.26], males: SMD 1.86 [0.79, 2.93], rats: SMD 1.51 [0.16, 2.87], mice: SMD 2.62 $[1.49,3.75])$. EPA levels were unaltered in the overall analysis, which is expected because the majority of studies did not supplement EPA. $\alpha$-Linolenic acid levels (precursor of DHA and EPA) were diminished probably as a consequence of omega-3 FA supplementation: SMD $1.54[-2.99,-0.10]$. However, this result was restricted to two studies performed by Hashimoto et al. [50, 55], and is also the cause of the gender difference observed in subgroup analysis (Fig. 5b). 
A

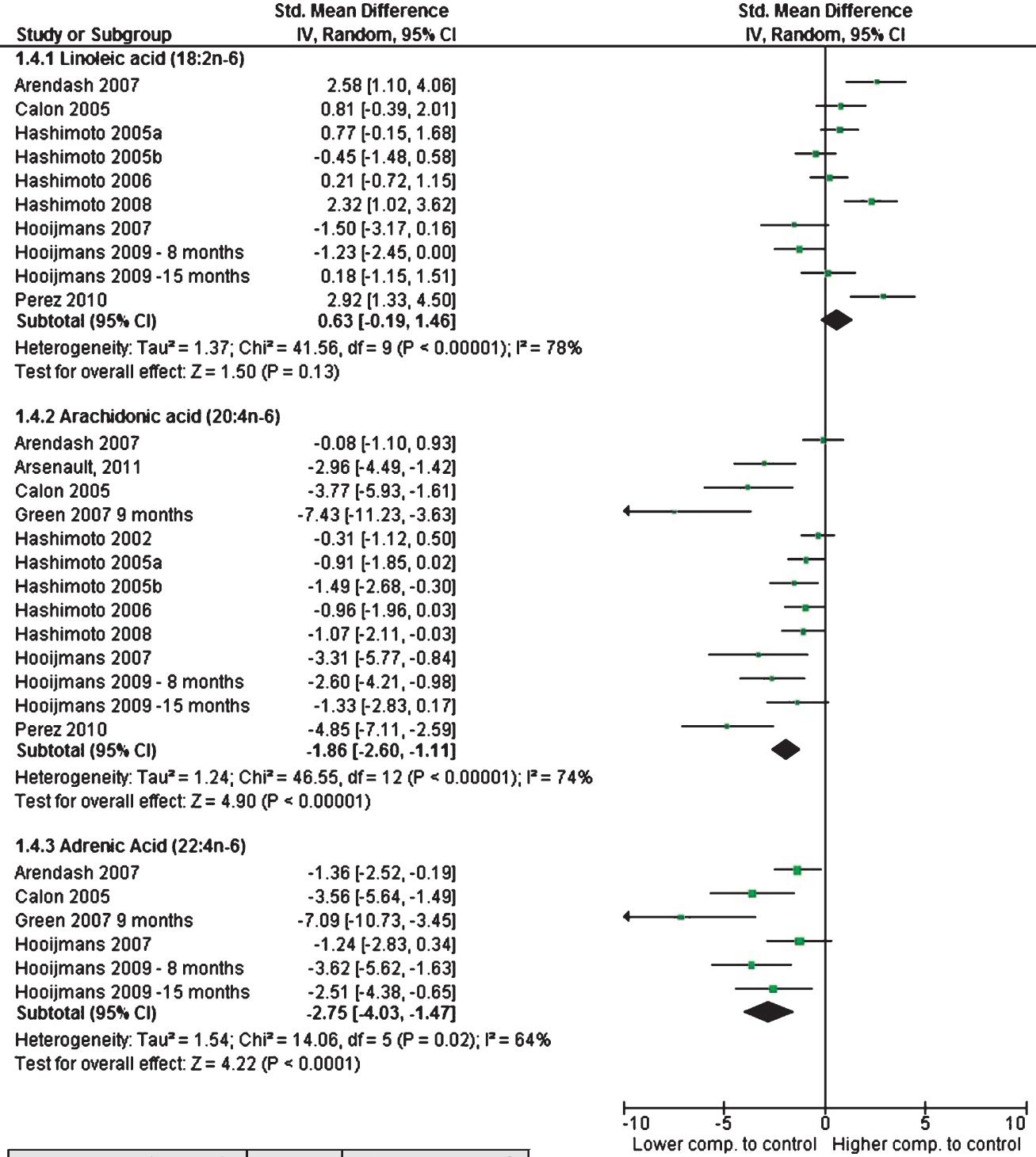

B

\begin{tabular}{|c|c|c|}
\hline Linoleic acid (18:2n-6) & $\mathrm{n}$ & Effect size and Cl \\
\hline Overall & 10 & $0.63[-0.19,1.46]$ \\
male & 7 & $0.09[-0.76,0.93]$ \\
female & 0 & ne \\
mixed & 3 & $2.03[0.67,3.39]$ \\
\hline Arachidonic acid (20:4n-6) & $\mathrm{n}$ & Effect size and Cl \\
\hline Overall & 13 & $-1.86[-2.60,-1.11]$ \\
male & 8 & $-1.11[-1.62,-0.60]$ \\
female & 0 & ne \\
mixed & 5 & $-3.49[-5.83,-1.15]$ \\
\hline Adrenic Acid (22:4n-6) & $\mathrm{n}$ & Effect size and Cl \\
\hline Overall & 5 & $-2.75[-4.03,-1.47]$ \\
male & 3 & $-2.35[-3.72,-0.98]$ \\
female & 0 & ne \\
mixed & 3 & $-3.56[-6.37,-0.75]$ \\
\hline
\end{tabular}

Fig. 4. (a) Forest plot (effect size and 95\% CI) and (b) subgroup analysis of individual studies of omega-3 FA supplementation on cortical omega-6 FA levels in experimental animal models of Alzheimer's disease. 


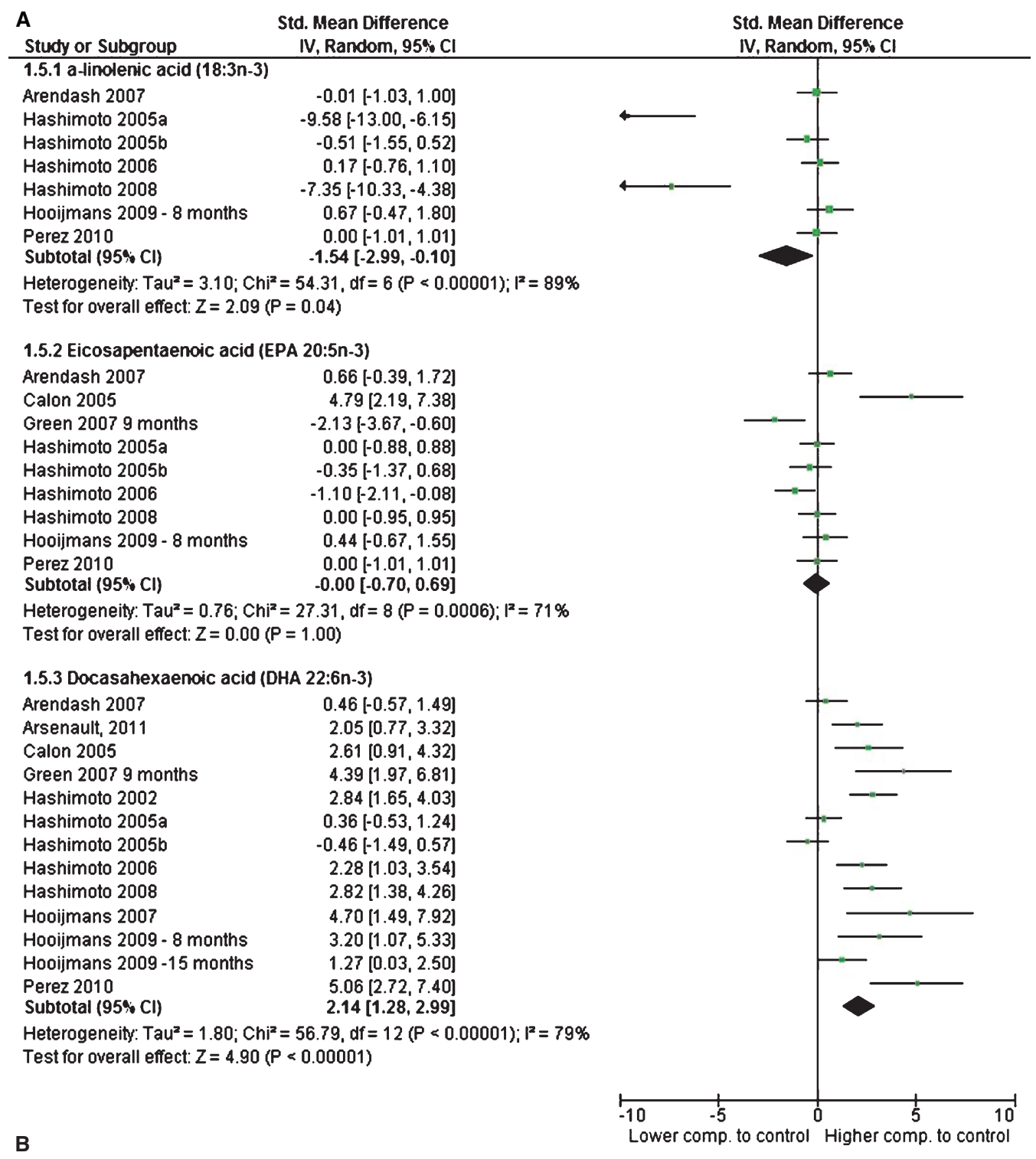

\begin{tabular}{|c|c|c|}
\hline$\alpha$-linolenic acid (18:3n-3) & $\mathrm{n}$ & Effect size and CI \\
\hline Overall & 8 & $-1.54[-2.99,-0.10]$ \\
male & 6 & $-2.67[-5.00,-0.34]$ \\
female & 0 & ne \\
mixed & 2 & $-0.01[-0.72,0.71]$ \\
\hline DHA (22:6n-3) & $\mathrm{n}$ & Effect size and CI \\
\hline Overall & 13 & $2.14[1.28,2.99]$ \\
male & 8 & $1.86[0.79,2.93]$ \\
female & 0 & ne \\
mixed & 5 & $2.67[1.09,4.26]$ \\
rats & 5 & $1.51[0.16,2.87]$ \\
mice & 8 & $2.62[1.49,3.75]$ \\
\hline
\end{tabular}

Fig. 5. (a) Forest plot (effect size and 95\% CI) and (b) subgroup analysis of individual studies of omega-3 FA supplementation on cortical omega-3 FA levels in experimental animal models of Alzheimer's disease. 


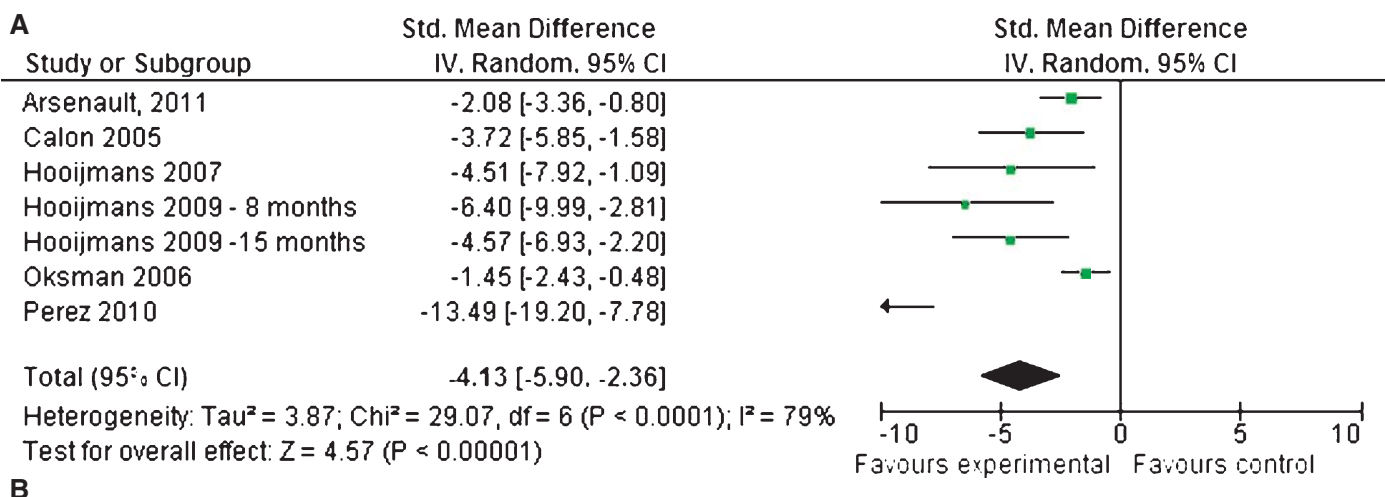

\begin{tabular}{|c|c|c|}
\hline$\eta 6 / \eta 3$ ratio & $\mathrm{n}$ & Effect size and CI \\
\hline Overall & 7 & $-4.13[-5.90,-2.36]$ \\
male & 4 & $-3.90[-6.37,-1.43]$ \\
female & 0 & ne \\
mixed & 2 & $-5.22[-9.13,-1.32]$ \\
mice & 6 & $-4.13[-5.90,-2.36]$ \\
rats & 0 & ne \\
\hline
\end{tabular}

Fig. 6. (a) Forest plot (effect size and $95 \%$ CI) and (b) subgroup analysis of individual studies of omega-3 FA supplementation on the ratio between omega- 6 and omega-3 FAs in experimental animal models of Alzheimer's disease.

Overall analysis of omega-6 and omega-3 FA levels was not performed because the overall result will be biased given that not all types of omega-3 and omega-6 FAs were taken into account in the included studies.

Omega-6/omega-3 ratio. Overall analysis of the studies investigating the omega-6/omega-3 ratio showed that this ratio decreased under influence of omega3 supplementation (Fig. 6a; SMD -4.13 [-5.90, $-2.36]$ ) due to a shift in the balance between omega-3 and omega- 6 FAs. The relative amount of omega6 FA decreased as the relative amount of omega-3 FA increased in experimental animal models for AD supplemented with omega-3 FA. Subgroup analysis revealed a possible gender effect of mixed gender (a lower ratio) compared to males (Fig. 6b; mixed gender: SMD -5.22 [-9.13, -1.32], males: SMD -3.90 $[-6.37,-1.43])$.

The meta-regression did not explain any of the heterogeneity at all with an R-squared of $7 \%$. There was no variation in species over the studies with this outcome measure, so this variable was not included in the model. The effect of gender remained, but precision was so low that the change in SMD was no longer more than one SEM.

\section{DISCUSSION}

The RCTs carried out so far [32-35] used shortterm supplementation (a maximum of $2 \%$ of the life expectancy of the participants in the largest and longest RCT [36] ever performed). Further, there are practical difficulties involved in RCTs studying long-term supplementation. Given these considerations, our SR of the literature has focused on the effects of relatively long-term omega-3 FA supplementation (a minimum of $10 \%$ of the life expectancy of mice and rats) on cognitive impairment, $A \beta$ pathology, neurodegeneration, and brain FA levels in animal models of AD.

This SR shows that relatively long-term omega-3 FA supplementation (during at least $10 \%$ of the expected life span in mice and rats) reduced the amount of $A \beta$ in the brain, improved cognition, and diminished the amount of neuronal loss in animal models for AD. In other words, long-term omega-3 FA supplementation suggests favorable effects on parameters related to $\mathrm{AD}$ in animal models.

In addition, subgroup analyses also revealed potential gender and species differences. For example: the effect of omega-3 supplementation on cognition seemed larger in rats compared to mice, and the diminished amount of neuronal loss due to omega-3 supplementation was largest in the mixed gender group compared to males alone. 
Finally, meta-regression showed that, for most of the outcomes, the heterogeneity in the results was not solely attributable to the variables included in the model. Gender did explain the heterogeneity in the results for neurodegeneration. However, the gender effects on both cognition and DHA levels disappeared in the meta-regression, suggesting confounding by species, which remained an effect modifier for these outcomes.

Fifteen studies concerning the effects of omega-3 FA supplementation in experimental AD were included in this SR. Therefore, this review contains on average $30 \%$ more relevant papers compared to the narrative reviews published in this field, which clearly shows the benefit of searching systematically. For most of the included studies, all the necessary data for metaanalysis were obtained from the papers or through contact with the author. The data about cognition could not be obtained from one study, which devaluates the strength of the results of the performed meta-analysis because the power diminished. Nevertheless we used the results of that study in a descriptive way, and the results supported our findings.

It is of importance that the results of published animal experiments, similar to those of clinical trials, are archived for at least 5-10 years and that scientists performing animal experiments will make their data available to encourage the carrying out of SRs in animal experimentation. The results of SRs will lead to much better interpretation of the available scientific results from animal studies, through which a better translation to the clinic and more guarantees for patient safety may become reality.

However, not only is there a need to improve access to the results of already published animal experiments, but also the scientific quality of the papers must be improved [56]. Key characteristics of scientific practice such as randomization, blinding, and description of withdrawals/dropouts are routinely published in most human clinical trials, but are often not mentioned in publications of animal studies. In our SR, $60 \%$ of the studies reported the use of randomization but none mentioned the method of randomization, only $6 \%$ of the studies mentioned blinding the outcome assessment, and in $20 \%$ the number of animals excluded per group were properly described. For scientific and ethical reasons towards animals and humans, it is urgent that standards that are routinely applied in human research are applied to animal research as well. Nevertheless, the results of the quality assessment performed in this SR should be carefully interpreted because this assessment was based on the published manuscript, and strictly speaking assessed the quality of reporting instead of the quality of the carrying out of the experiment. For this reason better reporting of animal studies is crucial, and it is of the utmost importance that recent initiatives in this field are implemented [56, 57]. Despite insufficient reporting, SRs and meta-analysis of current publications do provide us with valuable new insights, and aid in making possible bias transparent.

Our meta-analysis clearly shows that the ratio omega-6/omega-3 FA in brain tissue shifted in favor of omega-3 under influence of omega-3 FA supplementation in experimental AD models. This indicates a direct influence of dietary FA on the brain, demonstrating an exchange of long-chain polyunsaturated FAs across the blood brain barrier [58]. The overall analysis revealed that omega-3 FA supplementation (which was solely DHA supplementation in $86 \%$ of the studies) increased brain DHA levels. Three of the included experiments did not show an effect of omega-3 FA supplementation on DHA content in cortical brain tissue; however, they did show a significant increase in DHA brain levels in other regions or other fractions. The study by Hashimoto et al. [50] showed significant increased DHA levels in hippocampal tissue; a further study by Hashimoto et al. [46] showed that the mol\% of DHA and the detergent soluble fractions of the cortex significantly increased due to omega-3 FA supplementation. In the study by Arendash et al. [43], only the frontal cortex was sampled and they did not report any significant increase in DHA brain levels. It cannot be ruled out that, also in this study, hippocampal DHA could have been increased, but this remains pure speculation. Nevertheless, the sensitivity analysis revealed that excluding the study of Arendash et al. [43] or all three studies did not influence our overall results substantially (data not shown).

The observed relative increase of omega-3 FAs over omega-6 FAs may imply increased membrane fluidity [9]. Gray matter is composed of approximately $30-40 \%$ of DHA, which is almost $17 \%$ of the total weight of FAs in the brain. Because of this huge abundance of DHA in the brain, it can be expected that a significant increase of DHA in the brain as seen in this SR influences membrane fluidity. In previous studies, increased DHA concentrations in neuronal membranes have led to changes in the physical properties of membranes, enzyme activities, receptors, transport, and cellular interactions [59-61], and it is therefore possible that increased membrane fluidity also directly influences the production of $A \beta$.

Indeed, this SR shows that, overall, long-term omega-3 FA supplementation reduced the amount 
of $A \beta$. Eight of the included experiments showed significantly reduced $A \beta$ levels after omega-3 FA supplementation. The results of one experiment on the effects of omega-3 FA supplementation on $A \beta$ levels has not been included in this meta-analysis [62] because the paper was published after the completion of the meta-analysis. However, the results from that study are also in accordance with the results of the meta-analysis.

In this SR, the effects of omega-3 FA supplementation on cognitive functioning was also analyzed. From this analysis it became clear that omega-3 FA supplementation improved cognition in AD experimental animals. These results were in accordance with the results of the paper excluded from metaanalysis because the exact data could not be obtained. In that particular study [50], protective effects of DHA against impaired learning in $\mathrm{A} \beta$-infused rats were reported.

Nonetheless, it should be noted that, from the studies included in this meta-analysis investigating the effect of DHA on cognition in animal models of $\mathrm{AD}$, the studies with the largest effect sizes started omega-3 supplementation already before creating the experimental $\mathrm{AD}$ model (infusing $\mathrm{A} \beta$ peptide in the rat cerebral ventricle). This might indicate that DHA supplementation should be started early in life to generate the largest beneficial effects. Nevertheless sensitivity analysis revealed that, when the studies that started omega-3 supplementation before creating the experimental AD model were excluded from the meta-analysis, the overall effect on cognition remained significantly improved in animals supplemented with omega-3 supplemented compared to the controls (results not shown). The reasons for the beneficial effects of omega-3 FAs on cognition are largely unclear and are not the topic of this SR, but they could be the result of DHA-mediated neuroprotection [63]. Indeed, also in this SR we found a diminished amount of neuronal loss in $\mathrm{AD}$ animals supplemented with omega-3 FA compared to controls. Subgroup analysis of the outcome measure "cognition" revealed that this effect was larger in rats compared to mice. Although it is heavily debated whether rats are a better model to study cognition compared to mice, this SR indicates that a rat model might be more suitable/sensitive. However, all the rat studies included in this SR were carried out by the same research group using the same experimental AD model and rat strain (i.e., Wistar rat). Therefore, strictly we can only conclude that omega-3 FA supplementation improves cognitive functioning in A $\beta$-infused Wistar rats.
As mentioned before, a diminished amount of neuronal loss in AD animals supplemented with omega-3 FA compared to controls was observed. Elaborating on the mechanism underlying this DHA mediated neuroprotective effect would go beyond the scope of this SR. However, several mechanisms that might be responsible have been suggested and extensively discussed by others (reviewed in [62-64]). Subgroup analysis and meta-regression revealed that this effect was larger in the mixed gender group. Although, as noted before, the results from subgroup should be interpreted with caution and no strong conclusions can be drawn, this finding indicates a possible improved protection of females to neuronal loss due to omega-3 FA supplementation. The underlying mechanism responsible for this interesting if uncertain gender effect is unknown and should be investigated more in-depth in the future. However, it might be directly related to the amount of omega-3 FA in brain tissue, since the results from the brain FA analysis performed in this SR also suggested that females benefit more from omega-3 supplementation than males, although this effect could not be confirmed in the meta-regression analysis.

It could be suggested that neuronal loss is the cause of the alterations in cognition. However, if this were true, subgroup analysis for the outcome measure cognition should have revealed a gender effect in favor of females as well, which was not the case here. Subgroup analysis for cognition revealed a larger improvement of cognition in males compared to the mixed gender group, but this effect disappeared after correction for species in the meta-regression. Therefore, it could be proposed that a mechanism other than neuronal loss is responsible for the changes in cognition (e.g., changes in cerebral hemodynamics). Previously, one of our own studies has indeed shown that a DHAenriched diet changed vascular parameters (relative cerebral blood volume) before effects on $A \beta$ load and cognition were noted [39]. In addition, other studies showed that DHA is able to improve vascular conditions via lowering plasma triacylglycerol [64, 65], vascular reactivity $[64,66]$, and decreasing atherosclerosis $[67,68]$. These positive effects on the circulation may improve age- and AD-related hypoperfusion in the brain and in this way contribute to improvement of cognition. But other mechanisms could also be proposed (reviewed in [19, 69]). For example, omega-3 FAs also seem to have anti-oxidative, anti-inflammatory, and anti-apoptotic effects, which could be responsible for alterations in cognition. In addition, alterations in molecular signaling could be the cause. Omega-3 FAs seem to increase expression of CaMKII, CREB and 
glutamate receptors, which promote long-term potentiation to strengthen synaptic plasticity and ultimately improve cognitive function.

In this SR, we investigated the effect of omega-3 FAs on cognition and AD pathology in animal models of $\mathrm{AD}$. It should be noted, however, that, because of the large number of studies solely supplementing DHA and the few remaining studies supplementing a mixture of DHA and other omega-3 FAs, it could be suggested that our study results primarily reflect the effects of DHA, rather than of omega-3 FAs in general.

The sensitivity analysis (data not shown) revealed that when including only the studies which supplemented solely DHA in the meta-analysis, the overall results did not change. This suggests that the effects on cognition and AD pathology in this SR are probably mainly determined by the presence of DHA.

When selecting an animal model, it is important to keep in mind that the choice of a specific gender or species to study the effects of omega-3 FA supplementation should be dependent on the parameters that need to be investigated. On the basis of this SR it is suggested that, in case solely behavioral parameters for cognition are determined, it will be useful to choose an $A \beta$-infused rat model instead of a transgenic AD mouse model, whereas females instead of males in AD experiments might occasionally be better to study the often subtle effects on neurodegeneration. However, one should keep in mind that female animals are influenced by their hormonal cycle, which might influence behavior, body physiology and cognitive and learning-related performance, and which should be accounted for in the experimental design (e.g., increasing power and balanced randomization of the animals across groups, etc.). More generally, SRs provide extremely important information for choosing the best animal model for answering a specific research question. Therefore it is strongly recommended, whenever possible, to carry out a SR prior to deciding which animal model will give the best answer to a (clinical) research question $[56,70,71]$.

This SR also has some limitations. First, there is a chance of overestimation of the summary scores because in this SR only published studies are included, and of those the most extreme results were selected. Further, some studies of low methodological quality were used. Second, the data included in this SR are very heterogeneous largely due to the variation in study quality and experimental designs used (different species, ages, duration of supplementation, etc.). Although we have tried to account for that by using the random effect model and performing subgroup analysis and meta-regression, pooling of the results is probably not appropriate for all outcome measures. However, all studies provide information on the association between omega-3 FA supplementation and the development of AD. There is much debate as to whether variation increases or decreases the validity of the pooled results.

In summary, this SR showed that long-term omega3 FA supplementation to experimental rat and mouse AD models shifted the ratio omega-6/omega-3 FA in favor of omega-3, and reduced the amount of $A \beta$. In addition, omega-3 FA supplementation improved cognitive function, especially in rats. Last but not least, omega-3 FA supplementation diminished the amount of neuronal loss in animal models for $\mathrm{AD}$, and this effect seemed to be larger in female animals.

The above-mentioned results obtained from animal studies indicate that long-term supplementation of omega-3 FA, during a minimum period of $10 \%$ of total life span, may be beneficial for patients with advanced AD. This SR clearly illustrates the importance of carrying out a SR before choosing an animal model, since new information appears from such an analysis, i.e., the gender and species differences. This provides essential argumentation for the scientific decision which animal model suits best for answering a specific ([bio]medical) research question.

\section{ACKNOWLEDGMENTS}

We would like to thank all the authors who were willing to provide us with additional data. This study was financially supported by a research grant from the ZonMW program (Dierproeven begrensd) in the Netherlands (ZonMW is a scientific organization for health research and development; Grant No. 40-4010096-8002).

Authors' disclosures available online (http://www.jalz.com/disclosures/view.php?id=988).

\section{REFERENCES}

[1] Engelhart MJ, Geerlings MI, Ruitenberg A, Van Swieten JC, Hofman A, Witteman JC, Breteler MM (2002) Diet and risk of dementia: Does fat matter? The Rotterdam Study. Neurology 59, 1915-1921.

[2] Kivipelto M, Helkala EL, Laakso MP, Hanninen T, Hallikainen M, Alhainen K, Iivonen S, Mannermaa A, Tuomilehto J, Nissinen A, Soininen H (2002) Apolipoprotein E epsilon4 allele, elevated midlife total cholesterol level, and high midlife systolic blood pressure are independent risk factors for late-life Alzheimer disease. Ann Intern Med 137, 149-155. 
[3] Kivipelto M, Helkala EL, Laakso MP, Hanninen T, Hallikainen M, Alhainen K, Soininen H, Tuomilehto J, Nissinen A (2001) Midlife vascular risk factors and Alzheimer's disease in later life: Longitudinal, population based study. BMJ 322, 1447-1451.

[4] Luchsinger JA, Noble JM, Scarmeas N (2007) Diet and Alzheimer's disease. Curr Neurol Neurosci Rep 7, 366-372.

[5] Morris MC, Evans DA, Bienias JL, Tangney CC, Bennett DA, Aggarwal N, Schneider J, Wilson RS (2003) Dietary fats and the risk of incident Alzheimer disease. Arch Neurol 60 , 194-200.

[6] Morris MC, Evans DA, Bienias JL, Tangney CC, Bennett DA, Aggarwal N, Wilson RS, Scherr PA (2002) Dietary intake of antioxidant nutrients and the risk of incident Alzheimer disease in a biracial community study. JAMA 287, 3230-3237.

[7] Morris MC, Evans DA, Bienias JL, Tangney CC, Bennett DA, Wilson RS, Aggarwal N, Schneider J (2003) Consumption of fish and $n$ - 3 fatty acids and risk of incident Alzheimer disease. Arch Neurol 60, 940-946.

[8] Bourre JM, Dumont O, Piciotti M, Clement M, Chaudiere J, Bonneil M, Nalbone G, Lafont H, Pascal G, Durand G (1991) Essentiality of omega 3 fatty acids for brain structure and function. World Rev Nutr Diet 66, 103-117.

[9] Farkas E, de Wilde MC, Kiliaan AJ, Meijer J, Keijser JN, Luiten PG (2002) Dietary long chain PUFAs differentially affect hippocampal muscarinic 1 and serotonergic 1A receptors in experimental cerebral hypoperfusion. Brain Res $\mathbf{9 5 4}$, 32-41.

[10] Heron DS, Shinitzky M, Hershkowitz M, Samuel D (1980) Lipid fluidity markedly modulates the binding of serotonin to mouse brain membranes. Proc Natl Acad Sci U S A 77, 7463-7467.

[11] Yehuda S, Rabinovitz S, Mostofsky DI (1998) Modulation of learning and neuronal membrane composition in the rat by essential fatty acid preparation: Time-course analysis. Neurochem Res 23, 627-634.

[12] Ikemoto A, Ohishi M, Sato Y, Hata N, Misawa Y, Fujii Y, Okuyama H (2001) Reversibility of $n-3$ fatty acid deficiencyinduced alterations of learning behavior in the rat: Level of $n$-6 fatty acids as another critical factor. J Lipid Res 42, 1655 1663.

[13] Kyle DJ, Schaefer E, Patton G, Beiser A (1999) Low serum docosahexaenoic acid is a significant risk factor for Alzheimer's dementia. Lipids (34 Suppl), S245.

[14] Tully AM, Roche HM, Doyle R, Fallon C, Bruce I, Lawlor B, Coakley D, Gibney MJ (2003) Low serum cholesteryl esterdocosahexaenoic acid levels in Alzheimer's disease: A casecontrol study. Br J Nutr 89, 483-489.

[15] Soderberg M, Edlund C, Kristensson K, Dallner G (1991) Fatty acid composition of brain phospholipids in aging and in Alzheimer's disease. Lipids 26, 421-425.

[16] Cole GM, Ma QL, Frautschy SA (2009) Omega-3 fatty acids and dementia. Prostaglandins Leukot Essent Fatty Acids 81, 213-221.

[17] Fotuhi M, Mohassel P, Yaffe K (2009) Fish consumption, long-chain omega-3 fatty acids and risk of cognitive decline or Alzheimer disease: A complex association. Nat Clin Pract Neurol 5, 140-152.

[18] Boudrault C, Bazinet RP, Ma DW (2009) Experimental models and mechanisms underlying the protective effects of $n-3$ polyunsaturated fatty acids in Alzheimer's disease. $J$ Nutr Biochem 20, 1-10.

[19] Cunnane SC, Plourde M, Pifferi F, Begin M, Feart C, Barberger-Gateau P (2009) Fish, docosahexaenoic acid and Alzheimer's disease. Prog Lipid Res 48, 239-256.
[20] Barberger-Gateau P, Raffaitin C, Letenneur L, Berr C, Tzourio C, Dartigues JF, Alperovitch A (2007) Dietary patterns and risk of dementia: The three-city cohort study. Neurology $\mathbf{6 9}$, 1921-1930.

[21] Samieri C, Feart C, Letenneur L, Dartigues JF, Peres K, Auriacombe S, Peuchant E, Delcourt C, Barberger-Gateau P (2008) Low plasma eicosapentaenoic acid and depressive symptomatology are independent predictors of dementia risk. Am J Clin Nutr 88, 714-721.

[22] Schaefer EJ, Bongard V, Beiser AS, Lamon-Fava S, Robins SJ, Au R, Tucker KL, Kyle DJ, Wilson PW, Wolf PA (2006) Plasma phosphatidylcholine docosahexaenoic acid content and risk of dementia and Alzheimer disease: The Framingham Heart Study. Arch Neurol 63, 1545-1550.

[23] Barberger-Gateau P, Letenneur L, Deschamps V, Peres K, Dartigues JF, Renaud S (2002) Fish, meat, and risk of dementia: Cohort study. BMJ 325, 932-933.

[24] Kalmijn S, Feskens EJ, Launer LJ, Kromhout D (1997) Polyunsaturated fatty acids, antioxidants, and cognitive function in very old men. Am J Epidemiol 145, 33-41.

[25] Kalmijn S, Launer LJ, Ott A, Witteman JC, Hofman A, Breteler MM (1997) Dietary fat intake and the risk of incident dementia in the Rotterdam Study. Ann Neurol 42, 776-782.

[26] van Gelder BM, Tijhuis M, Kalmijn S, Kromhout D (2007) Fish consumption, $n-3$ fatty acids, and subsequent 5 -y cognitive decline in elderly men: The Zutphen Elderly Study. Am J Clin Nutr 85, 1142-1147.

[27] Huang TL, Zandi PP, Tucker KL, Fitzpatrick AL, Kuller LH, Fried LP, Burke GL, Carlson MC (2005) Benefits of fatty fish on dementia risk are stronger for those without APOE epsilon4. Neurology 65, 1409-1414.

[28] Kalmijn S, van Boxtel MP, Ocke M, Verschuren WM, Kromhout D, Launer LJ (2004) Dietary intake of fatty acids and fish in relation to cognitive performance at middle age. Neurology 62, 275-280.

[29] Morris MC, Evans DA, Tangney CC, Bienias JL, Wilson RS (2005) Fish consumption and cognitive decline with age in a large community study. Arch Neurol 62, 1849-1853.

[30] Nurk E, Drevon CA, Refsum H, Solvoll K, Vollset SE, Nygard O, Nygaard HA, Engedal K, Tell GS, Smith AD (2007) Cognitive performance among the elderly and dietary fish intake: The Hordaland Health Study. Am J Clin Nutr 86, 1470-1478.

[31] Beydoun MA, Kaufman JS, Sloane PD, Heiss G, Ibrahim J (2008) $n$-3 Fatty acids, hypertension and risk of cognitive decline among older adults in the Atherosclerosis Risk in Communities (ARIC) study. Public Health Nutr 11, 17-29.

[32] Freund-Levi Y, Eriksdotter-Jonhagen M, Cederholm T, Basun H, Faxen-Irving G, Garlind A, Vedin I, Vessby B, Wahlund LO, Palmblad J (2006) Omega-3 fatty acid treatment in 174 patients with mild to moderate Alzheimer disease: OmegAD study: A randomized double-blind trial. Arch Neurol 63, 14021408 .

[33] Chiu CC, Su KP, Cheng TC, Liu HC, Chang CJ, Dewey ME, Stewart R, Huang SY (2008) The effects of omega-3 fatty acids monotherapy in Alzheimer's disease and mild cognitive impairment: A preliminary randomized double-blind placebo-controlled study. Prog Neuropsychopharmacol Biol Psychiatry 32, 1538-1544.

[34] Kotani S, Sakaguchi E, Warashina S, Matsukawa N, Ishikura Y, Kiso Y, Sakakibara M, Yoshimoto T, Guo J, Yamashima T (2006) Dietary supplementation of arachidonic and docosahexaenoic acids improves cognitive dysfunction. Neurosci Res 56, 159-164.

[35] Quinn JF, Raman R, Thomas RG, Yurko-Mauro K, Nelson EB, Van Dyck C, Galvin JE, Emond J, Jack CR Jr, Weiner 
M, Shinto L, Aisen PS (2010) Docosahexaenoic acid supplementation and cognitive decline in Alzheimer disease: A randomized trial. JAMA 304, 1903-1911.

[36] Hooijmans CR, Tillema A, Leenaars M, Ritskes-Hoitinga M (2010) Enhancing search efficiency by means of a search filter for finding all studies on animal experimentation in PubMed. Lab Anim 44, 170-175.

[37] De Vries R, Hooijmans CR, Tillema A, Leenaars M, RitskesHoitinga M (2011) A search filter for increasing the retrieval of animal studies in Embase. Lab Anim 45, 268-270.

[38] Green KN, Martinez-Coria H, Khashwji H, Hall EB, Yurko-Mauro KA, Ellis L, LaFerla FM (2007) Dietary docosahexaenoic acid and docosapentaenoic acid ameliorate amyloid-beta and tau pathology via a mechanism involving presenilin 1 levels. J Neurosci 27, 4385-4395.

[39] Hooijmans CR, Van der Zee CE, Dederen PJ, Brouwer KM, Reijmer YD, van Groen T, Broersen LM, Lutjohann D, Heerschap A, Kiliaan AJ (2009) DHA and cholesterol containing diets influence Alzheimer-like pathology, cognition and cerebral vasculature in APPswe/PS1dE9 mice. Neurobiol Dis 33, 482-498.

[40] Perez SE, Berg BM, Moore KA, He B, Counts SE, Fritz JJ, Hu YS, Lazarov O, Lah JJ, Mufson EJ (2010) DHA diet reduces AD pathology in young APPswe/PS1 Delta E9 transgenic mice: Possible gender effects. J Neurosci Res 88, 10261040 .

[41] Egger M, Smith GD, Altman DG (2009) Systematic reviews in health care, Meta-analysis in context. BMJ publishing group.

[42] DerSimonian R, Laird N (1986) Meta-analysis in clinical trials. Control Clin Trials 7, 177-188.

[43] Arendash GW, Jensen MT, Salem N, Hussein N Jr, Cracchiolo J, Dickson A, Leighty R, Potter H (2007) A diet high in omega-3 fatty acids does not improve or protect cognitive performance in Alzheimer's transgenic mice. Neuroscience 149, 286-302.

[44] Calon F, Lim GP, Morihara T, Yang F, Ubeda O, Salem N Jr, Frautschy SA, Cole GM (2005) Dietary $n$-3 polyunsaturated fatty acid depletion activates caspases and decreases NMDA receptors in the brain of a transgenic mouse model of Alzheimer's disease. Eur J Neurosci 22, 617-626.

[45] Calon F, Lim GP, Yang F, Morihara T, Teter B, Ubeda O, Rostaing P, Triller A, Salem N Jr, Ashe KH, Frautschy SA, Cole GM (2004) Docosahexaenoic acid protects from dendritic pathology in an Alzheimer's disease mouse model. Neuron 43, 633-645.

[46] Hashimoto M, Hossain S, Agdul H, Shido O (2005) Docosahexaenoic acid-induced amelioration on impairment of memory learning in amyloid beta-infused rats relates to the decreases of amyloid beta and cholesterol levels in detergentinsoluble membrane fractions. Biochim Biophys Acta 1738, 91-98.

[47] Hashimoto M, Hossain S, Shimada T, Shido O (2006) Docosahexaenoic acid-induced protective effect against impaired learning in amyloid beta-infused rats is associated with increased synaptosomal membrane fluidity. Clin Exp Pharmacol Physiol 33, 934-939.

[48] Hashimoto M, Hossain S, Shimada T, Sugioka K, Yamasaki H, Fujii Y, Ishibashi Y, Oka J, Shido O (2002) Docosahexaenoic acid provides protection from impairment of learning ability in Alzheimer's disease model rats. J Neurochem $\mathbf{8 1}$, 1084-1091.

[49] Hashimoto M, Shahdat HM, Yamashita S, Katakura M, Tanabe Y, Fujiwara H, Gamoh S, Miyazawa T, Arai H, Shimada $\mathrm{T}$, Shido O (2008) Docosahexaenoic acid disrupts in vitro amyloid beta(1-40) fibrillation and concomitantly inhibits amyloid levels in cerebral cortex of Alzheimer's disease model rats. J Neurochem 107, 1634-1646.

[50] Hashimoto M, Tanabe Y, Fujii Y, Kikuta T, Shibata H, Shido O (2005) Chronic administration of docosahexaenoic acid ameliorates the impairment of spatial cognition learning ability in amyloid beta-infused rats. J Nutr 135, 549-555.

[51] Hooijmans CR, Rutters F, Dederen PJ, Gambarota G, Veltien A, van Groen T, Broersen LM, Lutjohann D, Heerschap A, Tanila H, Kiliaan AJ (2007) Changes in cerebral blood volume and amyloid pathology in aged Alzheimer APP/PS1 mice on a docosahexaenoic acid (DHA) diet or cholesterol enriched Typical Western Diet (TWD). Neurobiol Dis 28, 16-29.

[52] Lim GP, Calon F, Morihara T, Yang F, Teter B, Ubeda O, Salem N Jr, Frautschy SA, Cole GM (2005) A diet enriched with the omega-3 fatty acid docosahexaenoic acid reduces amyloid burden in an aged Alzheimer mouse model. J Neurosci 25, 3032-3040.

[53] Oksman M, Iivonen H, Hogyes E, Amtul Z, Penke B, Leenders I, Broersen L, Lutjohann D, Hartmann T, Tanila H (2006) Impact of different saturated fatty acid, polyunsaturated fatty acid and cholesterol containing diets on beta-amyloid accumulation in APP/PS1 transgenic mice. Neurobiol Dis 23, 563-572.

[54] Arsenault D, Julien C, Tremblay C, Calon F (2011) DHA improves cognition and prevents dysfunction of entorhinal cortex neurons in $3 \times \mathrm{Tg}$-AD mice. PLoS One 6, e17397.

[55] Hashimoto M, Shahdat HM, Yamashita S, Katakura M, Tanabe Y, Fujiwara H, Gamoh S, Miyazawa T, Arai H, Shimada T, Shido O (2008) Docosahexaenoic acid disrupts in vitro amyloid beta(1-40) fibrillation and concomitantly inhibits amyloid levels in cerebral cortex of Alzheimer's disease model rats. J Neurochem 107, 1634-1646.

[56] Hooijmans CR, Leenaars M, Ritskes-Hoitinga M (2010) A gold standard publication checklist to improve the quality of animal studies, to fully integrate the Three Rs, and to make systematic reviews more feasible. Altern Lab Anim 38, 167182.

[57] Kilkenny C, Browne WJ, Cuthill IC, Emerson M, Altman DG (2010) Improving bioscience research reporting: The ARRIVE guidelines for reporting animal research. $J$ Pharmacol Pharmacother 1, 94-99.

[58] Tsukada H, Kakiuchi T, Fukumoto D, Nishiyama S, Koga K (2000) Docosahexaenoic acid (DHA) improves the agerelated impairment of the coupling mechanism between neuronal activation and functional cerebral blood flow response: A PET study in conscious monkeys. Brain Res $\mathbf{8 6 2}$, 180-186.

[59] Yehuda S, Rabinovitz S, Carasso RL, Mostofsky DI (1998) Fatty acids and brain peptides. Peptides 19, 407-419.

[60] Yoshida S, Yasuda A, Kawazato H, Sakai K, Shimada T, Takeshita M, Yuasa S, Kobayashi T, Watanabe S, Okuyama $H$ (1997) Synaptic vesicle ultrastructural changes in the rat hippocampus induced by a combination of alpha-linolenate deficiency and a learning task. J Neurochem 68, 12611268.

[61] Youyou A, Durand G, Pascal G, Piciotti M, Dumont O, Bourre JM (1986) Recovery of altered fatty acid composition induced by a diet devoid of $n-3$ fatty acids in myelin, synaptosomes, mitochondria, and microsomes of developing rat brain. $J \mathrm{Neu}$ rochem 46, 224-228.

[62] Amtul Z, Uhrig M, Rozmahel RF, Beyreuther K (2011) Structural insight into the differential effects of omega-3 and omega- 6 fatty acids on the production of Abeta peptides and amyloid plaques. J Biol Chem 286, 6100-6107. 
[63] Oster T, Pillot T (2010) Docosahexaenoic acid and synaptic protection in Alzheimer's disease mice. Biochim Biophys Acta 1801, 791-798.

[64] Harris WS (1997) $n-3$ fatty acids and serum lipoproteins: Human studies. Am J Clin Nutr 65, 1645S-1654S.

[65] Sacks FM, Katan M. (2002) Randomized clinical trials on the effects of dietary fat and carbohydrate on plasma lipoproteins and cardiovascular disease. Am J Med 113 (Suppl 9B), 13S$24 \mathrm{~S}$.

[66] Goodfellow J, Bellamy MF, Ramsey MW, Jones CJ, Lewis MJ (2000) Dietary supplementation with marine omega-3 fatty acids improve systemic large artery endothelial function in subjects with hypercholesterolemia. J Am Coll Cardiol 35, 265-270.

[67] Okuda N, Ueshima H, Okayama A, Saitoh S, Nakagawa H, Rodriguez BL, Sakata K, Choudhury SR, Curb JD, Stamler J (2005) Relation of long chain $n-3$ polyunsaturated fatty acid intake to serum high density lipoprotein cholesterol among Japanese men in Japan and Japanese-American men in Hawaii: The INTERLIPID study. Atherosclerosis 178, 371379.

[68] von Schacky C, Harris WS (2007) Cardiovascular benefits of omega-3 fatty acids. Cardiovasc Res 73, 310-315.

[69] Su HM (2010) Mechanisms of $n-3$ fatty acid-mediated development and maintenance of learning memory performance. J Nutr Biochem 21, 364-373.

[70] Kobaek-Larsen M, Thorup I, Diederichsen A, Fenger C, Hoitinga MR (2000) Review of colorectal cancer and its metastases in rodent models: Comparative aspects with those in humans. Comp Med 50, 16-26.

[71] Ritskes-Hoitinga J, Meijers M, Meijer GW, Weststrate JA (1996) The influence of dietary linoleic acid on mammary tumour development in various animal models. Scand J LAS 23, 463-469. 